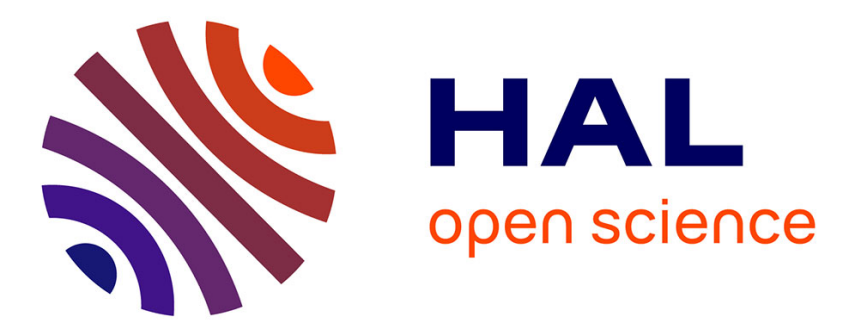

\title{
A simple paradigm for nooconomics, the economy of knowledge
}

Idriss J. Aberkane

\section{To cite this version:}

Idriss J. Aberkane. A simple paradigm for nooconomics, the economy of knowledge. CS-DC'15 World e-conference, Sep 2015, Tempe, United States. hal-01291105

\section{HAL Id: hal-01291105 \\ https://hal.science/hal-01291105}

Submitted on 20 Mar 2016

HAL is a multi-disciplinary open access archive for the deposit and dissemination of scientific research documents, whether they are published or not. The documents may come from teaching and research institutions in France or abroad, or from public or private research centers.
L'archive ouverte pluridisciplinaire HAL, est destinée au dépôt et à la diffusion de documents scientifiques de niveau recherche, publiés ou non, émanant des établissements d'enseignement et de recherche français ou étrangers, des laboratoires publics ou privés. 


\title{
A simple paradigm for nooconomics, the economy of knowledge
}

\author{
Idriss J. Aberkane \\ 1 \\ Unesco-Unitwin Complex Systems Digital Campus 7 rue René Descartes F-67000 \\ Strasbourg, France \\ Centre de Recherche en Gestion, Ecole Polytechnique Bâtiment Enta 828 Boulevard \\ des Maréchaux 91762 Palaiseau Cedex, France \\ Kozmetsky Global Collaboratory Stanford University Kozmetsky Family Center 224 \\ Panama Street (Nora Suppes Hall), Suite 104 Stanford University Stanford, CA \\ 94305-4110, USA \\ idriss.aberkane@polytechnique.edu
}

\begin{abstract}
The human noosphere and its inner dynamic are forming a fascinating yet poorly understood multiscale complex system, in which one may represent the interaction of individual knowledge holders and their collective dynamic. Here I propose a simple, improvable paradigm for noodynamics (the study of knowledge flows) and nooconomics at large (the economy of knowledge) based on two intrinsic properties of knowledge - its prolificity and collegiality and on three simple transfer laws capturing some fundamental differences between material and immaterial economics, namely 1) that knowledge exchanges, unlike property exchanges, are flows, and thus time-dependent, 2) that knowledge exchanges are positive sum, unlike material exchanges and 3) that combinations of knowledge are non linear. I then make a suggestion for a basic knowledge flow equation, namely that transferred knowledge is proportional to the product of spent attention and time, and discuss some of its social and political implications.
\end{abstract}

keywords: knowledge economy, noosphere, multiscale dynamic, knowledge flow, noodynamics

The purpose of this article is to outline a simple and improvable paradigm for noodynamics, the study of knowledge flows. If we endow this paradigm with an economic perspective, and consider its agents buyers and sellers, it can then also be considered an early working paradigm, or more precisely, an early building block towards a working paradigm, for nooconomics, the economy of knowledge. I thus attempt to demonstrate that noodynamics can be codified extremely simply, although not entirely, and will leave the many exceptions to the present paradigm to discussion. 
From an economic and political perspective, the reason to practice nooconomics is much-too-obvious, and it is that knowledge, just like human stupidity one may add, is infinite. The argument of knowledge's intrinsic infinity may be constructed as follows, from simple though not easily demonstrated premises: let us at least consider that any knowledge of knowledge is another knowledge (ie. that knowing has no fixed point), then one can establish that the universe of all possible knowledge has a non surjective injection within itself, and that it is thus infinite. This of course leaves the question of its boundedness open. A more elegant demonstration would be that the powerset of any set of knowledge is making for distinct knowledge and thus, that for any set of knowledge, a distinct powerset - which is mathematically larger, can be constructed. The notion of serendipity, which I will use later as one of the fundamental principles of noodynamics, can also allow the construction of a sound argument that human knowledge is potentially infinite, as the possible serendipities of a knowledge set are calculated over elements of its powerset.

Thus still, from an economic and political point of view, knowledge may very well be the only potentially infinite resource that is offered to Humanity. We know very well that infinite growth is impossible if it is purely based on raw materials, which are finite, even when they are renewable, granted that we still consider time finite. But infinite growth is not impossible if it is knowledge-based. The question of global economic growth's current confrontation with the ecosphere's material finiteness can indeed be transcended by the question of better allocating our growth between material and immaterial origins. Besides, the ecosphere, much more than a source of raw materials, is also a source of knowledge in itself.

\section{Basic noodynamics}

Probably the most basic property of knowledge exchanges is what we may call "Soudoplatoff's law", after its many formulations by Internet entrepreneur Serge Soudoplatoff when he worked for IBM in 1984. Although many scholars and philosophers must have been aware of it in the past, especially since it was well stated by Sufi master Amadou Hampâté Bâ and understated in one of the famous Mollah Nasruddin stories - and indeed there are several laws that were named after not their first, but their clearer presenters - Soudoplatoff has made, in my sense, the clearest formulation of it in recent years, and simpler for the layman than the economically-consecrated "non-rivalry of non-material goods" of Lawrence Lessig.

\section{Soudoplatoff's law}

when one shares a material good, one divides it. When one shares an immaterial good, one multiplies it.

As we will see, this law may also be captured in one of the three laws of noodynamics that I outline here. Since knowledge is an immaterial good indeed, sharing it does not divide it, but rather multiplies it and also makes it evolve. Knowledge therefore, may not be considered a thing but rather a process, in a manner comparable to the process 
of life. Its economics, also, is one of fluxes rather than one of stocks, in which ownership must clearly be redefined.

Soudoplatoff's law has many non-trivial implications. From a geopolitical perspective, one must admit that most of the conflicts that Humanity has been knowing have been a consequence of that sharing a material good implies its division. Be the good a piece of meat, a reserve of freshwater, an oil deposit or mere territory, the fact that sharing something material divides it has been an endless, and certainly the very most prolific source of conflicts. From the perspective of sustainable development also, Soudoplatoff's law very well underlines the economic and political interest of biomimicry: if one considers the ecosphere a source of raw materials, then indeed, anything that is taken from it is divided. If it is otherwise considered a source of knowledge, then anything that is taken from it is multiplied. Thus, the very political interest of biomimicry is indeed that it is a form of economic development, knowledge-based in nature, that does not imply the destruction of nature but rather its protection.

Since nooconomics is an economy of fluxes rather than of stock, it is interesting to remark that the legal ownership of knowledge is very different from its practical ownership. One may own a library, even as the depositor or heir of its intellectual property, but one may not have read its books. Knowledge also, could be defined in many ways: the tongue-in-cheek one of Idries Shah "knowledge is something you can use, belief is something that uses you", the classical one of Socrates and Plato, namely the intersection between belief and reality, the "KID" paradigm of Peter Drucker, that Information (I) is Data (D) endowed with relevance and purpose, and that converting D into I requires Knowledge $(\mathrm{K})$, or finally we may place all these categories of the knowledge economy along a continuous differential spectrum beginning with data and ending with wisdom. The perspective on data can generate information, the perspective on information can generate knowledge, the perspective on knowledge can generate wisdom, which is not time-dependent, interestingly. Another simple way to separate between information and knowledge is that knowledge is reproducible while information is not.

In any case, just as it can be extremely difficult to define numbers per se, yet easy to establish a simple paradigm for arithmetics, we may not attempt to define knowledge, but merely the relations that its study encompasses. The study of these relations establishes noodynamics. Of course that noodynamics and nooconomics be so much interrelated makes them a very exciting paradigm, as if economics and thermodynamics had been plainly entangled from the very beginning of their conceptual inception.

It remains interesting to remark that information is essentially more perishable than knowledge, which regards the laws of the universe. Yet although knowledge does not really perish, it can be made obsolete by better, transcendant knowledge. Wisdom in turn, the perspective on knowledge, or in the classical definition, self-knowledge, is not even dependent upon space and time.

Another implication of Soudoplatoff's law is to be considered in models of bargaining power, such as the classical forces of Michael Porter, and in the behaviour of maximising agents in general. Indeed, maximising agents are to be expected to behave 
differently when bargaining over something material and something immaterial. What is to be expected of maximising agents in nooconomics? This is an interesting open scholarly question.

\section{A simple paradigm for nooconomics}

Let us consider first at least two fundamental social properties of knowledge.

Property 1 - Prolificity

Knowledge is prolific; it is growing exponentially

There is somehow a kind of biology to knowledge, and it surely has an exponential growth... which again from a malthusian point of view is a very good thing. As a rule of thumb, we may consider the list of newly-solved problems a reliable correlate of the "quantity" of knowledge (not its "quality" indeed, which may only be assessed in futurum, as one rarely knows in advance which knowledge will turn out revolutionary or crucial), and this list in itself has a doubling time of about seven to nine years. In The Technopolis Phenomenon, venture capitalist Regis McKenna already considered in 1991 that this doubling time, which is clearly dynamic in itself, was of 10 years. The doubling time of the quantity of scientific publications coming from the People's Republic of China is of five years for example, although the list of truly solved problems is a much more accurate correlate of the knowledge mass than the latter.

\section{Property 2 - Collegiality}

Humanity makes knowledge collegial, namely "truth is a shattered mirror" and everybody owns a bit. Since human beings - and especially more so regarding academics one must admit - have an ego, they display two very counter-productive tendencies with respect to optimal noodynamics. First human beings tend to consider "their little bit the whole to own", and second, they tend to resist the collectivisation of knowledge, which projects such as Wikipedia have still demonstrated to be of tremendous benefit to Humanity. Academic peer-review in this respect is also proving extremely immature in process and mindset, in that it should evolve into peerimprovement, rather than pass-or-fail admission/rejection, a process that belongs to a time when the limitation on publications was merely coming from that on available printing space.... and also from an era where hypertext and modification mark-up did not exist. An economic model properly rewarding peer-improvers remains to be developed however.

Knowledge is a shattered mirror, of which everybody owns a bit, and it is in the most fundamental interests of nooconomists to favour the dynamic collectivisation of it. Noocollectivism, interestingly enough, is of course profoundly different from the collectivisation of material goods, once again owing to Soudoplatoff's law, and dogmatically speaking, me be more considered the result of laissez-faire than dirigisme. 
Let us now establish at leat three fundamental laws of noodynamics. From a social perspective two of them are excellent news, and one of them is bad news.

\section{Law 1 - Positive Sum}

Knowledge exchanges are positive sum. This is a re-expression of Soudoplatoff's law: when I give away say 20 euros, I lose them. When I give away knowledge, I do not. Material exchanges are null sum, immaterial exchanges, such as knowledge exchanges, are positive sum. This, of course, is excellent news.

\section{Law 2 - Not instantaneous}

Property exchanges may be considered instantaneous, and of course, scalable. It takes virtually the same time to transfer the ownership of 20 euros or 20 million euros, e.g. a signature, whether physical or electronic. Exchanges of legal ownership are thus virtually instantaneous so much so that the current legal limitation to their frequency, that of high-frequency trading, is the nanosecond. However, there is no highfrequency trading in nooconomics, because knowledge exchanges take time. It takes time to read this article, it cannot be acquired at high-frequency yet. Thus knowledge exchanges, unlike properties exchanges, are flows. This may be considered either a bad news (so far) or a fertile opportunity, that of the technology-driven increasing of the micro and macro knowledge flows, in which neuroergonomics is destined to play a major role.

\section{Law 3 - Superlinear}

Property compositions may be linear in general. This is of course not true from a venture capitalist's point of view, in that an entrepreneurial project is more that the sum of its parts. But from a saver's point of view adding one kilograms of rice to another kilograms of rice is something linear, and makes two kilograms of rice. As long as processes are not involved thus, property composition is linear. Adding one thousand euros to an account already credited with one thousand euros makes two thousand euros. This does not apply to knowledge compositions however, precisely in that knowledge is a process. The composition of two bits of knowledge systematically generates a third one, which is anywhere between trivial (but non-null) and revolutionary.

We may capture this property with the simple inequality

$$
\mathrm{K}(\mathrm{A} \wedge \mathrm{B})>\mathrm{K}(\mathrm{A}) \wedge \mathrm{K}(\mathrm{B})
$$

"knowing A and B together is more than knowing A and knowing B separately", which does not apply to "owning" from a saver's point of view.

Knowledge may thus be considered to "reproduce" in a way, and the difference between knowing two things separately and knowing them together may be called the "fertility" of knowledge, which is somehow comparable to the notion of entrepreneurial added value. This fertility accounts for the intrinsic prolificity of knowledge. Since 
knowledge is always action-oriented indeed, and not something to save in nature, its composition shares some close similarities with that of entrepreneurial means. We may also oversimplify our paradigm by calling the fertility of knowledge "serendipity", that is, the fortuitous creation of novel knowledge from the collision of several distinct bits of knowledge, although it remains unsure whether serendipity covers all of the fertility of knowledge. Is all the fertility of knowledge the result of serendipity? This question may prove very scientifically fertile in itself.

I know introduce what I consider to be the simplest possible non-trivial knowledge flow equation. It will at least apply to the knowledge flow of any reader of this article, or of any audio-visual or haptic content (such as the Braille writing), or of any Wikipedia article, for which one may also call this knowledge flow equation the "Wikipedia equation". Its construction is very intuitive and straightforward: what is it that we spend indeed in acquiring conceptual knowledge from a book, a video game or a course? Attention and time. Since these two currencies of nooconomics are crucial to each other and must be spent together to achieve any result, the amount of flowed knowledge is surely not proportional to their sum, but rather to their product, in that spending one hour and zero attention surely implies a null transfer, and spending all one's attention for less than even the subliminal perceptual threshold also implies a null flow. If one admits, along with Dehaene and others, that there are at least three qualitatively distinct levels of arousal, namely subconscious, preconscious and conscious (the possibility of more advanced states of consciousness is not at all negated), then one could formulate the following equation:

Equation 1 - Simplest knowledge flow - from an economic point of view

$$
\varphi(\mathrm{k}) \propto \mathrm{At}
$$

"the amount of flowed knowledge follows the product of attention and time"

Some constants c1, c2 and c3 would then be left each to account for a different level of cortical arousal, so as to distinguish clearly subliminal learning from conscious learning. And since attention, just as numbers and knowledge, is hardly well-defined per se today but rather in its relation to other scientific objects such as consciousness (with which it may one day be fully united scientifically), one may, for the moment, simply scale the attention factor (A) from zero to one. The product of attention and time becomes the most essential currency of nooconomics. The unity of attention in the knowledge flow equation could be called "deciPosner" or "deciDehaene" in the manner of the decibel, but this choice will be left to the community.

The unity of the product At, as the fundamental currency of knowledge transfers, should also be given a simple name. In this article I will simply call them Ats, or @ ${ }^{1}$. $1 @$ is equal to one hour at full attention (whatever its range, subliminal, preconscious or conscious, them being defined by the constants used in the equation and not by the

\footnotetext{
${ }^{1}$ two horizontal strokes may be added so as to indicate one @ is a currency
} 
A variable), namely an attention of 1 . How could we measure attention from an economic point of view? Maximal attention, intuitively, is achieved when one is so much taken by what he is doing that he misses any external stimulus (eg. you are so absorbed by a book that you miss your subway station). Otherwise a correlated measure of foveation (eye-tracking) and cortical arousal could be an introduction to such a problem in cognitive neurosciences, but there are surely much simpler ways to extract empirical measures of attention. The key to their finding will surely be to distinguish between collective (macro), where the law of large numbers may apply, and individual (micro) attention, with the study of the mesoscopic scale a very exciting problem of nooconomics.

The knowledge flow equation has many interesting economic and political implications. One of them is bad news, and mostly all of the others are excellent news. We may understand them with the thought experiment of a "knowledge marketplace" (which the Internet has clearly become) as opposed to a "material marketplace". The difference between regular capital and knowledge capital (@) is that, with regular capital, if one visits a marketplace and buys nothing, one's purchasing power has remained essentially the same, which is not the case with knowledge capital, since one, visiting a knowledge marketplace yet buying nothing, would still have spent time and thus reduced one's purchasing power. Knowledge capital flies whether it is used or not, unlike regular capital, and this is the bad news. The economy of knowledge is not one of savings, but one of revenues.

One behavioural difference between a regular marketplace and a knowledge one is the counter-intuitive relation between envy and purchasing power as limiting agents in the purchasing act. In purchasing a commercial good, purchasing power is the main limitation, not envy, which marketing attempts to maximise for any good. In a knowledge marketplace however, purchasing power is not quite the practical behavioral limitation, but envy is. When having to chose between say, a Wikipedia page on photonic molecules and something much more attention-enticing online, the average spender of @ may not easily choose the former... unless he or she is passionate about photonics molecules, and this is an interesting point of nooconomics.

The good news of course is that anybody is born with a certain, non null quantity of (a) in his or her lifetime. The knowledge economy is the only one in which everybody is naturally born with a non null purchasing power, assuming an equal access to the knowledge marketplace, a simplification made all the more realistic by the advent of the Internet. Nooconomics is also, thus, a paradigm in which the prime limitation to the act of buying is not purchasing power but desire.

If @ is the unit of purchasing power in nooconomics, it becomes possible to establish a price tag for any symbolic knowledge online, from learning a new language to knowing how to cook traditional French food to handling algebraic topology. One could consider the global knowledge marketplace a global "app store" in which anybody can virtually download any app into their brain, granted they pay enough@. Interestingly, knowing in advance how many @ a certain knowledge costs can also be a tremendous incentive or motivator. Let us say that, before@s were consider, anybody wanting to learn something was like someone ordering a dish from a menu with no price tags. Also, one must note that in nooconomics, the unemployed intrinsi- 
cally enjoys more purchasing power than those in work, having more@ to spend. This should be closely studied in the field of public policy, as it provides the basis for a straightforward conversion between poverty and wealth under certain conditions.

Since Beck and Davenport have elsewhere defined that attention is the "new currency of business", their is also a two-sided dimension to the spending of @ in a knowledge market, since receiving@ is convertible into money, and spending@ is convertible into knowledge. Buying knowledge, to a certain extent, is also creating regular capital, though a decaying one; this forms a fascinating bridge between classical economics and nooconomics. All in all, though, nooconomics seems just as different from classical economics than quantum mechanics was from classical physics.

If we consider maximising agents in nooconomics, we can also observe the interesting conditions under which individuals will maximise their knowledge flow. Under which circumstances do we maximise our expenditures of attention and time indeed? Undoubtedly, the supreme circumstance is love, and the one right under it is addiction (all love is addictive but not any addiction is love). Thus, nooconomics is the only economic paradigm maximising the purchasing power of those who are in love. As da Vinci clearly reminded, the origin of knowledge is love. And since addiction, right below it, is also a maximiser of knowledge flows, (video) games end up being remarkable "nooducts", namely aqueducts of knowledge, with a very high bandwidth. If knowledge is the new oil, surely (video) games are the new pipeline, and neuroergonomics a fascinating new fluid dynamics.

\section{Conclusion}

The fertility of nooconomics, as a paradigm, lies in the many original scientific problems it poses. One could already consider that the knowledge flow equation I have introduced does not capture any kind of flows. Indeed, it lacks a notion of synergy: what if the entrant knowledge resonates with already existing knowledge? Surely one should consider this case, in which the knowledge flow could exhibit a form of positive or negative feedback. Attention could either increase or decrease through time, but surely attention is in itself a function of time, which this initial equation does not consider. Thus, one could probably suggest the following equations instead:

Equation 2 - Simplest knowledge flow with dynamic attention

$$
\varphi(\mathrm{k}) \propto \mathrm{A}(\mathrm{t})
$$

Equation 3 - Simplest knowledge flow with synergy

\footnotetext{
2 in this case $\varphi(k)$ represents a flow in the physical meaning of "instant quantity being transferred", not in the economic meaning of "total transferred quantity"
} 


$$
\varphi(\mathrm{k}) \propto \mathrm{A}(\mathrm{t})+\operatorname{Syn}(\mathrm{k}, \mathrm{t})
$$

Where Syn $(\mathrm{k}, \mathrm{t})$ would represent the interference between entrant and preexisting knowledge at a given time (whether positive or negative). Also just as some enzymes may be "michaelian" or "non-michaelian", some knowledge flows may be simply captured by the non-synergic regime (equation 1), and others not. I suppose a more general theory of noodynamics could be eventually captured by equations in the form of:

Equation 4 - Outline for a general theory of knowledge flows (general noodynamics)

$$
\varphi(\mathrm{k}) \propto \operatorname{Res}(\mathrm{Sp}, \mathrm{Ev})
$$

Where the flow of knowledge is proportional to the resonance (Res) between the spontaneous ( $\mathrm{Sp}$ ) and evoked (Ev) activities of the brain, or the learning system at large (thus, why not, considering the knowledge flow of such other cognitive systems as the immune system for example, and not only the sentient brain). In such an equation however, both the Res operator and the variables Sp. and Ev. remain to be defined.

Other interesting questions will regard the macroeconomics and political economy of knowledge flows. For example, if global knowledge has a dynamic doubling time, and that the individual knowledge flow is in the form of Equation 1, what does it predict in terms of the macroscopic equilibria human groups (such as organizations, or states...) should achieve? Should states aim to equate their variation of the knowledge flow with the velocity of knowledge, or with the size of the noosphere (global knowledge) itself? From a microeconomics perspective, what does the fundamental attention-knowledge transaction of individual agents imply (namely, any knowledge-giver is an attention receiver), especially in terms of cognitive and behavioural psychology? Could we eventually develop a working paradigm for mesoscopic nooconomics?

\section{References}

1. Acs, Z.J., de Groot, H.L.F., and Nijkamp, P. (2002). The Emergence of the Knowledge Economy: A Regional Perspective (Springer).

2. Adler, P.S. (2001). Market, hierarchy, and trust: the knowledge economy and the future of capitalism. Organization Science 12, 215-234.

3. Amidon, D.M. (2009). Innovation Strategy for the Knowledge Economy (Taylor \& Francis).

4. Boden, M., and Miles, I. (2000). Services and the Knowledge-based Economy (Continuum).

5. Brown, P., Hesketh, A., and Williams, S. (2004). The Mismanagement of Talent: Employability and Jobs in the Knowledge Economy (OUP Oxford).

6. Burton-Jones, A. (2001). Knowledge capitalism: Business, work, and learning in the new economy. OUP Catalogue. 
7. Carayannis, E.G., Kaloudis, A., and Mariussen, A. (2008). Diversity in the Knowledge Economy and Society: Heterogeneity, Innovation and Entrepreneurship (Edward Elgar Publishing, Incorporated).

8. Clarke, T. (2001). The knowledge economy. Education+ Training 43, 189-196.

9. Cooke, P. (2001). Regional innovation systems, clusters, and the knowledge economy. Industrial and Corporate Change 10, 945-974.

10. Cooke, P., and Piccaluga, A. (2006). Regional Development in the Knowledge Economy (Taylor \& Francis).

11. Cunningham, M. (2006). Exploiting the Knowledge Economy: Issues, Applications and Case Studies (IOS Press).

12. Cunningham, P.M. (2007). Expanding the knowledge economy: issues, applications, case studies (IOS Press).

13. Cunningham, P., and Cunningham, M. (2004). Eadoption and the Knowledge Economy: Issues, Applications, Case Studies (IOS Press).

14. Cunningham, P., Cunningham, M., and Fatelnig, P. (2003). Building the Knowledge Economy: Issues, Applications, Case Studies (IOS Press).

15. Dahlman, C.J., and Aubert, J.E. (2001). China and the Knowledge Economy: Seizing the 21 st Century (World Bank).

16. Dahlman, C.J., Utz, A., and Institute, W.B. (2005). India and the Knowledge Economy: Leveraging Strengths and Opportunities (World Bank).

17. Davenport, T.H., and Beck, J.C. (2013). The Attention Economy: Understanding the New Currency of Business (Harvard Business Review Press).

18. Dehaene, S., Changeux, J.-P., Naccache, L., Sackur, J., and Sergent, C. (2006a). Conscious, preconscious, and subliminal processing: a testable taxonomy. Trends in Cognitive Sciences 10, 204-211.

19. Dehaene, S., Izard, V., Pica, P., and Spelke, E. (2006b). Core knowledge of geometry in an Amazonian indigene group. Science 311, 381-384.

20. Dolfsma, W., and Soete, L. (2006). Understanding the Dynamics of a Knowledge Economy (Edward Elgar Publishing, Incorporated).

21. Doz, Y.L., Santos, J., and Williamson, P. (2001). From Global to Metanational: How Companies Win in the Knowledge Economy (Harvard Business School Press).

22. Drahos, P., and Braithwaite, J. (2002). Information Feudalism: Who Owns the Knowledge Economy? (Earthscan).

23. Dunning, J.H. (2002). Regions, globalization, and the knowledge-based economy (Oxford University Press).

24. Etzkowitz, H., and Leydesdorff, L.A. (1997). Universities and the global knowledge economy.

25. Formica, P. (2004). Strengthening the Knowledge Economy: Essays on Knowledge Policy and International Entrepreneurship (EffElle Editiion).

26. Jaffe, A.B., and Trajtenberg, M. (2002a). Patents, Citations, and Innovations: A Window on the Knowledge Economy (MIT Press).

27. Jaffe, A.B., and Trajtenberg, M. (2002b). Patents, citations, and innovations: A window on the knowledge economy (MIT press).

28. Jägers, P.H., Jansen, W., and Steenbakkers, W. (2012). New Business Models for the Knowledge Economy (Ashgate Publishing, Limited).

29. Julien, P.A. (2008). A Theory of Local Entrepreneurship in the Knowledge Economy (Edward Elgar Publishing, Incorporated).

30. Kenway, J., Bullen, E., Fahey, J., and Robb, S. (2006). Haunting the Knowledge Economy (Taylor \& Francis).

31. Lengnick-Hall, M.L., and Lengnick-Hall, C.A. (2003). Human Resource Management in the Knowledge Economy: New Challenges, New Roles, New Capabilities (BerrettKoehler).

32. Leydesdorff, L. (2006). The Knowledge-based Economy: Modeled, Measured, Simulated (Universal Publishers). 
33. Luque, E. (2001). Whose knowledge (economy)? Social Epistemology 15, 187-200.

34. Meier, A. (2012). eDemocracy \& eGovernment: Stages of a Democratic Knowledge Society (Springer).

35. Neef, D. (1998). The knowledge economy (Butterworth-Heinemann).

36. Powell, W.W., and Snellman, K. (2004). The knowledge economy. Annual Review of Sociology 199-220.

37. Romer, P.M., and Kurtzman, J. (2004). The knowledge economy. In Handbook on Knowledge Management 1, (Springer), pp. 73-87.

38. Rooney, D., Hearn, G., and Kastelle, T. (2012). Handbook on the Knowledge Economy (Edward Elgar Publishing, Incorporated).

39. Schienstock, G. (2004). Embracing the Knowledge Economy: The Dynamic Transformation of the Finnish Innovation System (Edward Elgar Publishing, Incorporated).

40. Shattock, M., and Planning, I.I. for E. (2009). Entrepreneurialism in Universities and the Knowledge Economy (McGraw-Hill Education).

41. Spelke, E., Lee, S.A., and Izard, V. (2010). Beyond core knowledge: Natural geometry. Cognitive Science 34, 863-884.

42. Stewart, J., Tansley, C., and Development, C.I. of P. and (2002). Training in the Knowledge Economy (Chartered Institute of Personnel and Development).

43. Virginia, R.C.A.P.M.M.I.S.C.U., Organizations, A.P.R.C.I.B.M.I.K.B., and Organizations, L.S.R.C.I.B.M.I.K.B. (2003). Networks in the Knowledge Economy (Oxford University Press, USA).

44. Westeren, K.I. (2012). Foundations of the Knowledge Economy: Innovation, Learning and Clusters (Edward Elgar)

45. Westlund, H. (2006). Social Capital in the Knowledge Economy: Theory and Empirics (Springer). 